\title{
LA OCCIDENTALIZACIÓN DE LOS SIETE SABIOS DE ROMA Y SU DIFUSIÓN PENINSULAR: EL EJEMPLO DE VIRGILIUS
}

\author{
WESTERN CHANGES IN THE SEVEN SAGES OF ROME \\ AND ITS PENINSULAR SPREADING: THE VIRGILIUS' SAMPLE
}

NuRIA ARANDA García
Universidad de Zaragoza

Resumen: El Sendebar, nombre genérico con el que se conoce a una colección de cuentos de origen oriental, gozó de gran difusión durante el periodo medieval. Tras la escisión en dos ramas, la oriental Sendebar y la occidental Siete sabios de Roma, la obra penetrará en la Península a partir de versiones de esta última, donde será objeto de traducciones al castellano que evidencian una serie de cambios orientados a la adaptación de la colección a un ideario medieval más puramente occidental y la versatilidad de la estructura narrativa. El análisis en última instancia del cuento Virgilius constituye el ejemplo más representativo de este proceso y una clave más de su éxito en el tiempo.

Palabras clave: Sendebar, Siete sabios de Roma, difusión, traducciones castellanas, Virgilius.

\begin{abstract}
Sendebar is the common name given to a framed collection of tales which knew a great spreading during Medieval Times. After splitting in two main branches, the Eastern Sendebar and the Western Seven sages of Rome, some versions of the latter entered in the Iberian Peninsula and went through Castilian translations. Nevertheless, these new forms show some changes that remark the adaptation to a very European Western ideology and the flexible narrative structure. The study of the tale Virgilius is, finally, the most representative outcoming of this procedure and another success key through time.
\end{abstract}

Key words: Sendebar, Seven sages of Rome, spreading, Castilian translations, Virgilius. 


\section{Introducción*}

El interés por la cuentística de origen oriental en Europa resurge a finales del siglo XVIII fruto de la preocupación por sacar a la luz este tipo de colecciones de cuentos para presentarlas al público de la época, hecho que conducirá a su progresiva recuperación. Sin embargo, para encontrar una cierta atención por parte de los investigadores y la aparición de los primeros estudios críticos será necesario esperar, irremediablemente, hasta finales del siglo XIX y principios del siglo Xx, momento en el que se intensifican las investigaciones y se profundiza en las distintas versiones derivadas de sus ramas de transmisión.

La anónima Historia de los siete sabios de Roma, como colección con estos orígenes, es una muestra más de ese complejo proceso de difusión que sufrieron muchas obras gestadas en la Edad Media o que conocieron gran éxito durante este periodo. Surgida como colección en Oriente entorno al siglo IX, conoció múltiples variantes y traducciones, ya fuese en lengua latina o en vernáculas europeas, fundamentalmente gracias a la versatilidad que garantizaba una obra de autoría anónima que podía prestarse a lecturas e interpretaciones muy variadas. En la Península Ibérica, gracias a las particulares circunstancias históricas, la obra fue conocida a través de versiones tanto en su rama oriental, como en su rama occidental. Como resultado de ello en última instancia, la colección supo introducirse en el selecto grupo de obras medievales que dio el salto a la imprenta, primero como incunable en el siglo xv y posteriormente como texto impreso, haciéndose un hueco en el mercado editorial renacentista y en el mercado literario español durante cuatro siglos.

El objetivo de este trabajo, por tanto, no es otro sino ofrecer un panorama sobre la vida medieval peninsular de esta obra mediante una aproximación a su historia, a su presencia en la Península y al proceso de occidentalización que vivió, y que cuenta entre sus ejemplos más representativos el caso de Virgilius, una de las narraciones insertas más populares de la colección y que sintetiza parte del imaginario medieval occidental.

* El presente trabajo se ha realizado en el marco de las ayudas para la Formación de Profesorado Universitario (FPU) dentro del subprograma de formación y movilidad del Ministerio de Educación, Cultura y Deporte (FPU014/01331), y del proyecto de Investigación FFI2012-32259, de cuyo equipo de trabajo formo parte. 


\section{Una aproximación a la historia del Sendebar:} los orígenes de la colección

Los Siete sabios de Roma ${ }^{1}$ se remontan en sus orígenes al Sendebar, título genérico con el que se conoce a una colección de cuentos gestada inicialmente en Oriente y que conoció una gran difusión en Europa durante el periodo medieval, llegando a superar esa barrera temporal.

Pese a su arduo recorrido a través del tiempo y a los cambios propios de un complejo proceso de transmisión, el argumento y la estructura de la obra se mantienen más o menos intactos en la mayoría de las versiones conservadas: un emperador deseoso de tener un hijo consigue finalmente su propósito y lo entrega al cuidado de unos sabios, cuyo número varía en función de los distintos testimonios de la historia, para que se ocupen de darle una educación digna de un buen futuro soberano. La emperatriz fallece y el rey vuelve a contraer matrimonio con una nueva mujer que le pide que traiga al príncipe de vuelta. Antes del retorno, los sabios consultan los astros y descubren que el infante deberá permanecer siete días sin pronunciar palabra para poder salvar la vida. La madrastra, aprovechando el silencio del joven príncipe, finge que este la ha intentado forzar y convence al emperador para que condene a su propio hijo a muerte. A partir de este momento comenzará un intercambio dialéctico de historias entre la madrastra y los siete sabios a lo largo de los siete días, a través del cual la emperatriz intentará conseguir que el infante muera antes del plazo previsto, mientras que los sabios intentarán convencer al emperador de la maldad de las mujeres. Finalmente, el tiempo se agota y el infante consigue defender su propia postura narrando a su vez una serie de historias, al final de las cuales la madrastra será condenada a muerte.

Desde el punto de vista genérico y estructural, el Sendebar pertenece a las colecciones de cuentos conocidas con el nombre común de novela-marco, composiciones que se articulan en torno a un doble diseño narrativo que implica, a su vez, una doble vertiente: un relato-marco que aporta el nombre al género y se configura como la historia general, y un argumento que llama de alguna manera a la inserción de una serie de historias que interrumpen el decurso narrativo y que son narradas por personajes pertenecientes al relato prin-

1 La mayor fuente bibliográfica sobre los Siete sabios de Roma, su difusión y las variantes y versiones de los distintos ciclos es la ofrecida por la Society of the Seven Sages, disponible en H.R. Runte, K. Wikeley y F. Farrell (1984). 
cipal. Es el propio hilo argumental el que proporciona las herramientas fundamentales para favorecer esa inserción de narraciones secundarias en una posición definida, y el que cierra el desarrollo general del relato mediante una conclusión general (Lacarra, 1979: 50-51). En este tipo de composiciones es la unión del marco narrativo y las narraciones insertas la que configura el sentido completo de la colección de cuentos, por lo que, a pesar de que las narraciones insertas puedan conocer una vida independiente de su marco y garanticen cierta flexibilidad, mientras se encuentren como parte integrante de un relato principal adquirirán un significado específico al servicio de la historia. La mayor o menor fuerza unificadora que ejerza la historia principal sobre los relatos insertos y la mayor o menor subordinación de estos marcará distintos tipos de novela-marco, siendo el Sendebar uno de los ejemplos más perfectos, pues las narraciones condicionan en todo momento las decisiones que toman los personajes (Jaunzems, 1978: 45). ${ }^{2}$

El complicado proceso de transmisión del Sendebar dio lugar a la escisión en dos ramas principales, la rama oriental y occidental, distinción establecida por la crítica decimonónica. La primera de ellas, de origen oriental, será conocida bajo la denominación Sendebar, nombre que recibe el filósofo y sabio en torno al cual gira la educación del príncipe protagonista. De esta vertiente, cuyos orígenes todavía no han podido ser esclarecidos, ${ }^{3}$ conservamos ocho versiones, incluida una en castellano, que se remontarían en última instancia a una versión perdida redactada en árabe entre los siglos viII y X.

Esta traducción castellana fue llevada a cabo en el siglo XIII en el contexto de la Castilla alfonsí de la mano de don Fadrique, hermano de Alfonso X, bajo el título de Libro de los engaños, la única traducción conocida en España

2 Antecedentes de esta estructura se encuentran también en la literatura grecolatina, pero un ejemplo similar al Sendebar en la novelística oriental serían los deseos de Sherezade de cambiar su sino en las Mil y una noches.

3 Son tres las principales tesis defendidas sobre los posibles orígenes del Sendebar. Loiseleur-Deslongschamps (1838), y Benfey (1966) posteriormente, plantearon un posible origen sánscrito de la obra, amparándose en paralelismos entre algunos relatos del Sendebar y otros pertenecientes a la literatura india y en la correspondencia de algunos nombres con ciertas voces sánscritas. Epstein (1958; 1959; 1967) consideró el origen hebreo como más probable, aludiendo a una posible versión hebrea datada de los siglos IV-II a.C previa a la persa, de la cual habría partido. Perry (1959-1960), por su lado, expuso como hipótesis una redacción persa que habría emigrado hacia el este y se habría fundido con colecciones indias hasta dar lugar finalmente a la versión árabe. Artola (1978) rechazó la tesis de Perry, pero no excluyó la idea de una posible composición en pahleví por un copista anónimo sin conocimientos suficientes de sánscrito y sin posibilidad de haber consultado por ello ningún manuscrito en sánscrito de la obra. 
perteneciente al ciclo oriental y la primera realizada en lengua romance. ${ }^{4} \mathrm{El}$ infante don Fadrique, como ordenante de la traducción, contó como punto de partida con una versión árabe del texto, actualmente desconocida, y llevó a cabo la traslación en $1253^{5}$ en el ambiente cultural de una Sevilla que había sido reconquistada durante el reinado del Santo Monarca.

La traducción en sí no deja de ser algo defectuosa si la comparamos las salidas del taller alfonsí, amparado por la tradición previa de la Escuela de Traductores de Toledo y por un atento trabajo de supervisión lingüística. La versión castellana del Sendebar que conservamos no muestra ese cuidado, aunque no se deberían dejar de lado las posibles deturpaciones y contaminaciones de los copistas (Lacarra, 1989: 20-21).

Pese a tratarse de una colección de cuentos, erróneo sería pensar que nos encontramos ante una obra de carácter infantil o juvenil. Obras de similares características que se tradujeron en la época fueron consideradas como guías de conducta y recopilaciones sapienciales especialmente dirigidas hacia las clases dirigentes, de ahí que a menudo fuesen comisionadas por reyes o gente perteneciente a la nobleza. Este didactismo y el carácter persuasivo favorecieron que en muchas ocasiones muchos de los cuentos se difundiesen y se popularizasen de forma aislada o como parte de ejemplarios más elaborados. Taravacci (2003: 30), en este caso, considera al Sendebar oriental como «una testimonianza della complessità sostanziale e delle potenzialità dell'exemplum nella Spagna del secolo XIII».

El marco narrativo de la obra gira en torno a la educación del joven príncipe, y su desarrollo supone un entronque de motivos folclóricos y mitológicos vinculados estrechamente con los ritos de iniciación del héroe, como la predicción de horóscopo antes o después del nacimiento o la esterilidad prolongada (Rank, 1981: 79), y aglutina también rasgos típicos de la educación india como la relación individual entre maestro y discípulo. La finalidad última del infan-

4 El título Libro de los engaños e asayamientos de las mujeres se lo proporcionó Amador de los Ríos, el primer estudioso en describir el texto. La obra se conserva en un único manuscrito datado del siglo XV e inserto en un códice que perteneció al conde de Puñonrostro, actualmente en propiedad de la Real Academia Española. Esta traducción (h.64r-80v) comparte espacio con un abanico muy variado de textos entre los que se encuentra El Conde Lucanor.

5 Tal y como puede leerse en el prólogo de la obra: «El ynfante don Fadrique, fijo del muy noble aventurado e muy noble rrey don Fernando, de la muy santa rreyna conplida de todo bien doña Beatriz (...) plogo e tovo por bien que aqueste libro [fuese trasladado] de aravigo en castellano para aperçebir a los engañados e los asayamientos de las mujeres. Este libro fue trasladado en noventa e un años», vid. Lacarra, 1979: 30-31. 
te protagonista sería adquirir los conocimientos necesarios de su maestro para penetrar en el mundo de los adultos y ocupar la posición que le corresponde de acuerdo con su condición social. ${ }^{6}$ Esto sería extrapolable a la Castilla del siglo XIII, donde la traducción entroncaría con la preocupación por la educación de los futuros soberanos surgida sobre todo durante el periodo carolingio, pues Carlomagno fue considerado como el prototipo de príncipe perfecto. España se convertirá en pionera en la traducción de este tipo de tratadística de origen oriental a lenguas modernas y el Sendebar, por tanto, se vinculará con el género de los Specula Principis o guías para la formación del perfecto soberano (Lacarra, 1979: 35-36).

Tal y como es perceptible en el argumento de la obra y en algunos cuentos de la colección, los monarcas en el periodo de su difusión, y en especial a partir de Fernando III, se rodearán de sabios que actuarán como consejeros políticos y morales que intentarán transmitir sus saberes y conseguir que muestren las cualidades exigibles en el soberano perfecto, esto es, la mesura y la justicia frente a la saña y la precipitación, opuestos que mueven también al rey protagonista. El objetivo último no sería otro sino crear un modelo perfecto en el que los súbditos puedan verse reflejados.

En torno a la transmisión del saber giraría también la labor traductora desempeñada por el infante don Fadrique con el Sendebar. Esta tendría como protagonista la imagen del libro, centro de las culturas cristiana, judía y musulmana, considerado una de los caminos hacia la inmortalidad y vehículo de conocimiento por dotar de fama a aquellos que lo promueven (Lacarra, 1979: 101-106). El deseo último de don Fadrique habría sido alcanzar esa inmortalidad, labrarse un camino hacia la fama y consolidar su prestigio cultural y social a través de la escritura como vehículo hacia la vida eterna, ligando su nombre a la idea de saber y el conocimiento (Taravacci, 2003: 11). ${ }^{7}$

Por otro lado, el contenido misógino, visible en el conjunto de la obra, ha sido el aspecto que más ha llamado la atención de la crítica, hasta el punto de

Se ejemplifica en las historias conclusivas, donde el infante muestra que ha superado finalmente los ritos iniciáticos, ha alcanzado el estatus de héroe y puede finalmente ocupar el puesto que le corresponde de acuerdo al sistema de valores de su época, $c f$. Lacarra y Cacho Blecua, 1977: 242.

7 El afán de inmortalidad al que aspiraba el infante don Fadrique se basa en la idea de que los sabios nunca mueren, sino que perviven gracias a la fama obtenida por sus obras. Esta es la idea que se hace presente al final del proemio del Sendebar castellano: «el ynfante don Fadrique (...) por quanto nunca se perdiese el su bien nombre (...) tomo la entençion en fin de los saberes: tomo una nave enderesçada por la mar en tal que non tomo peligro en pasar por la vida perdurable». Esta metáfora náutica aúna las ideas del saber y la inmortalidad, $c f$. Lacarra, 1979: 31 . 
eclipsar las líneas anteriores, y queda reflejado en el título que se le dio a la traducción castellana: Libro de los engaños e los assayamientos de las mujeres. En el siglo XIII hubo tendencia a degradar la figura de la mujer y a mostrarla como personaje engañoso, no solo en la cuentística oriental, sino también en la tratadística moral occidental mediante argumentos tomados de Aristóteles, algo deturpados, explicaciones fisiológicas como la teoría de los humores o argumentos de los Padres de la Iglesia (Lacarra, 1986: 347-350).

El prototipo femenino que aparece en el Sendebar se corresponde con el tipo preferido de los relatos misóginos, «esposa infiel» o adúltera frustrada, ejemplificada en la madrastra del infante y en las mujeres que aparecen en las narraciones de los consejeros (Lacarra, 1986: 339-340). Estas mujeres, que no dudarán en idear cualquier artificio para burlar al marido y salir airosas de cualquier situación de adulterio, tendrán como contraposición dentro del relato a la esposa casta con condición de madre, por su analogía con la Virgen María, quien se librará del tratamiento misógino por ser perpetuadora de la estirpe masculina (Vilchis, 2004: 47-48). ${ }^{8}$

La misoginia, por lo tanto, no tendría un papel predominante. Su función dentro de la colección estaría supeditada a la educación de los gobernantes y a la adquisición del estatus de sabio. Para ser el soberano perfecto es necesario alejarse de cualquier contacto con las mujeres en el plano espiritual y físico. El carácter misógino no estaría tanto en los cuentos, fiel reflejo de la esposa adúltera, sino en el objetivo de los consejeros de desacreditar a la mujer y convertir al rey en un buen soberano sabio, justo y prudente (Lacarra, 1986: 347).

La finalidad última del Sendebar sería ilustrar los peligros que puede correr un soberano cuando pierde de vista la verdadera sabiduría, se deja condicionar por la opinión de una mujer y sucumbe a la prisa y a las decisiones precipitadas. Sería una llamada de atención hacia los soberanos y los nobles sobre los riesgos a los que se enfrenta quien ostenta una posición en el poder y el gobierno de un reino. Igualmente, como traducción de una colección de cuentos de origen oriental con el árabe como lengua de partida no deja de constituir un hecho anecdótico. Este tipo de cuentística, conjuntamente con los tratados ético-morales con la misma procedencia, se introducirá en Europa de forma mayoritaria en latín, como se verá a continuación.

8 La contraposición entre estos dos tipos de mujeres le sirvió a la Iglesia, sobre todo en el siglo XIII, para educar a la mujer casada y para alertar al varón y dotarlo de herramientas por si quisiese repudiar a su mujer legítima. Vid. Cándano Fierro, 1995: 2-3. 


\section{La Historia de los siete sabios de Roma y su contexto de recepción en la Península}

La rama occidental de transmisión del ciclo surge en el momento en el que la colección de cuentos comienza su propagación por Europa. Su importancia indiscutiblemente es mayor que la de su homóloga oriental, ya sea por el número de familias derivadas del ciclo, ya por su pervivencia a lo largo del tiempo.

Se desconocen todavía las circunstancias que pudieron haber propiciado el paso de la colección a Occidente para conformar este último ciclo, se considera que la primera versión ya propiamente occidental habría circulado por Europa en fechas no posteriores a $1150 \mathrm{y}$ en una lengua que muy probablemente habría sido el latín o el francés (Campbell, 1975: xviii), aunque permanece en la oscuridad la versión oriental que pudo haber servido de modelo y punto de partida. ${ }^{9}$ Sobre los agentes que propiciaron la transmisión también existen conjeturas, ${ }^{10}$ pero el papel decisivo recayó indudablemente en la transmisión oral, que sería independiente de las diversas redacciones del texto, ya que la mayor parte del material que dio lugar a la reelaboración en Occidente circulaba previamente en Europa a través de la oralidad. La flexibilidad de la estructura narrativa habría propiciado la no coincidencia de la mayor parte de los cuentos entre ambos ciclos e incluso los cambios de posición en los narradores. ${ }^{11}$

Para encontrar traducciones castellanas de versiones occidentales del ciclo será necesario esperar hasta el siglo xv, momento en el que la cuentística de origen oriental penetra de nuevo en la Península pero con propósitos claramente distintos a los que encontramos en la colección cuando es traducida en el

9 Un sector de la crítica llamó la atención sobre las similitudes que presenta la rama occidental y la versión hebrea del ciclo oriental, que se distancia en muchos aspectos de las restantes versiones. Por otro lado, una de las tesis más aceptadas es la propuesta por Gaston Paris, quien considera como origen del ciclo occidental la versión griega a través de Bizancio y de una reelaboración llevada posiblemente a cabo en Roma con nuevos materiales, $c f$. Cañizares, 2011: 22-23. Pese a todo, ante la ausencia de la versión que pudo haber servido de pieza de engarce, permanecemos en el terreno de la hipótesis.

10 Algunos autores consideran que fueron los mongoles los principales divulgadores de la literatura india, y a ellos se debe la difusión de la obra, mientras que estudiosos como Campbell (1975) prefieren darle un papel prominente a las Cruzadas como vía para la introducción de cuentos budistas. Los defensores de la tesis hebrea abogan más bien por los Radanitas como agentes primordiales para la difusión del Sendebar en Occidente. $C f$. Lacarra, 1979: 29.

11 Senescalcus, una de las narraciones internas de la colección, es un ejemplo claro de los cambios de narrador, pues en algunas versiones aparece en boca de uno de los sabios y en otras es narrado por la madrastra, vid. Haro Cortés (2015). 
siglo XIII. Cabe destacar que el siglo XV constituyó una bisagra en la recepción y valoración de la cuentística de origen oriental, llegando a marcar la que sería su forma definitiva una vez superada la barrera del paso a la imprenta.

El siglo xv, además, abrió un nuevo camino hacia las traducciones de muchas obras, cuya fortuna osciló en función del ámbito de difusión y de un mayor o menor acercamiento a los gustos predominantes de los lectores de la época. Estas traducciones se han denominado «retraducciones», término acuñado por Carlos Alvar (2010) para hablar de todas aquellas obras que conocieron una traducción inicial -como ocurrió con el Libro de los engaños- y que, con el paso de los siglos, cayeron en el olvido y fueron nuevamente trasladadas al castellano. Las nuevas versiones que resurgen «frecuentemente suponen un gran distanciamiento temporal y geográfico» $\mathrm{y}$ «exigen una diacronía y una diatopía que muchas veces lleva consigo notables alteraciones del texto debidas a la acomodación a nuevas mentalidades, a propósitos diversos o a culturas diferentes» (Alvar, 2010: 250). ${ }^{12}$

Las «retraducciones» que se llevaron a cabo en el siglo Xv de versiones occidentales de los Siete sabios gozaron de mejor o peor destino dependiendo de factores de diversa índole, pero estrechamente relacionados con la naturaleza del texto de origen, la manera en la que se llevó a cabo la traducción o la adscripción genérica de la obra resultante. Las traducciones, por tanto, se articularán, no como un proceso mecánico, sino como un proceso dinámico donde el protagonismo lo ostentarán la recepción del texto y los potenciales lectores.

La Historia de los siete sabios de Roma, así como sus homólogas europeas, puede considerarse como la «retraducción» más importante de la rama occidental. ${ }^{13}$ Como traducción anónima surgida expresamente por y para su difusión impresa, proviene del texto latino Historia septem sapientum Romae, perteneciente a la rama más prolífica este ciclo y a la más importante desde el

12 Un ejemplo análogo de «retraducción» es el ofrecido por el Calila e Dimna, compañero oriental del Libro de los engaños. Fue traducido al castellano por primera vez en el siglo XIII por Alfonso X y será trasladado de nuevo al castellano en el siglo xv, esta vez procedente del latín con el título de Exemplario contra los peligros del mundo y vinculado a las prensas de los hermanos Hurus.

13 Conocemos otra «retraducción» de los Siete sabios realizada por Diego de Cañizares también en el siglo xv. El punto de partida es la versión de la colección contenida en la Scala Coeli, un ejemplario compilado por el dominico Juan Gobi el Joven a principios del siglo XIV. La obra resultante de la traducción se enmarca en la corriente italianizante que había penetrado en la corte de Juan II, de ahí que no sorprenda que se presente con el término «novella». En cuanto al género, el resto de obras contenidas en el mismo códice facticio, tales como las Heroidas de Ovidio o el Siervo libre de amor muestran una cierta deriva de la obra al género sentimental. Su difusión en un círculo culto muy restringido dio lugar a que la obra no obtuviese el éxito esperado. Vid. Cañizares, 1999a; 1999b; 2011. 
punto de vista de la transmisión textual de la obra; ya sea por el número de traducciones conservadas en lenguas vernáculas, ya sea por una proyección en el tiempo que supera ampliamente a otras versiones. El texto de partida, datado en el primer tercio del siglo XIV, ya había conocido gran difusión en forma manuscrita e incunable e incluso integrado en los Gesta Romanorum, considerado por muchos uno de los factores que aseguró éxito de la obra (Roth, 2000: 91-93).

La inclusión o no de explicaciones moralizantes o reductiones al comienzo o al final de cada relato de la colección en la transmisión manuscrita, y el mayor o menor grado de fragmentación del texto han permitido establecer una clasificación entre aquellos manuscritos que sirvieron de apoyo a la predicación como una compilación más de exempla, y aquellos que tuvieron como destinataria una determinada comunidad espiritual y, por tanto, no fueron usados con fines homiléticos, sino para la lectura silenciosa (Roth, 2000: 101107). Esta adaptación del texto a diversos fines no es sino una muestra más de la versatilidad de la obra, cuyo éxito se verá ratificado por su paso a la imprenta en forma incunable, fundamentalmente en las prensas alemanas y flamencas, cuna de los primeros incunables, y por su difusión en el territorio francés (Cañizares, 2011: 114). Será en estos países donde surjan las primeras traducciones de obras a lenguas vernáculas, incluidas las de los Siete sabios, como resultado del potencial que creyeron ver los impresores en estas composiciones. Pese a ello, las traducciones francesas, algo más tardías, contaron entre las más exitosas, de ahí que muy posiblemente fuese un incunable francés el modelo para la traducción castellana. ${ }^{14}$

En la Península, la labor de la imprenta como medio más propicio para la difusión del texto escrito comenzó a adquirir fuerza en el último tercio del siglo Xv, hecho que llevó a muchos impresores extranjeros afincados en los reinos peninsulares a buscar posibles caminos para ampliar su mercado. $\mathrm{Su}$

14 La ciudad de Lyon tuvo cierta hegemonía y fue eje fundamental del comercio librario de Francia, por ser una pieza de engarce con los mercados del norte de Europa, fundamentalmente los alemanes, y punto de encuentro entre los mercaderes de Centroeuropa, Italia y España. Entre esa ciudad y nuestro país se forjaron una serie de relaciones que favorecieron el intercambio de obras y la entrada de numerosos incunables, muchos de ellos en lengua francesa y de temática variada, incluida la oriental. Además, la ciudad de Zaragoza en el comercio librario de finales del siglo xv constituyó un enclave importante para el paso y difusión de obras entre el otro lado de los Pirineos y el reino de Castilla, además de ser un relevante centro mercantil y tener muy profesionalizado el sector del libro; hecho que atrajo a numerosos trabajadores extranjeros vinculados con ese ámbito. Vid. Cañizares, 2011: 177-178 y M. A. Pallarés, 2003: 307. 
punto de mira se centrará en un público no muy familiarizado con el latín, lo cual supondrá una novedad con respecto al enfoque que habían adoptado en un primer momento impresores de otros países de Europa. Por ello, los impresores peninsulares se inclinaron hacia una estrategia editorial basada en la presentación de obras ya existentes previamente, procedentes muchas de ellas del periodo medieval y conocidas por el público, para darlas a conocer bajo la fachada de nuevos géneros literarios que captasen la atención de los lectores no doctos, protegidas en muchas ocasiones bajo la anonimia o la autoría dudosa dependiendo del mayor o menor éxito de la obra.

La Historia de los siete sabios de Roma ${ }^{15}$ se imprime por primera vez en Zaragoza en las prensas de los hermanos Hurus entre 1488 y $1491^{16}$ con el objetivo de cosechar el éxito de sus vernáculas equivalentes. Posiblemente la editio princeps, se trata de un ejemplar cuya manufactura alemana es evidente en las 32 xilografía enmarcadas que contiene, serie que procede de la imprenta de Anton Sorg en Ausburgo y que había sido preparada expresamente para la traducción alemana de 1480 , por lo que posiblemente fue prestada a los Hurus o dada en alquiler (Lacarra, 2014: 136-137).

En cuanto al texto de la traducción, mantiene el número y tipo de relatos insertos presentes en el modelo latino de la Historia septem sapientum Romae. En palabras de Cañizares (2011: 185), sería una «traducción invisible», una traducción en la que ni el traductor ni la traducción son perceptibles por el lector con el objetivo de potenciar la obra en el mercado editorial, y justificar así las posibles libertades que se hubiesen podido tomar con el texto. La obra, con pequeñas modificaciones sobre todo de carácter léxico, llegará a principios del siglo Xvi a la imprenta de los Cromberger en Sevilla, donde iniciará un proceso de transmigración genérica y reescritura, que ya se había empezado a intuir en su transmisión textual medieval, que la llevará a una longeva vida y éxito de cuatro siglos.

Sobre la recepción de la traducción, cabe destacar que a principios del siglo xv la cuentística de origen medieval, al menos en lo que concierne a su presencia

15 Ediciones del texto pueden consultarse en Gómez Palencia (1946), De la Torre Rodríguez (1990) y, posteriormente (1993) y Cañizares (2011). Estas ediciones tuvieron el impreso de 1530 como punto de partida. Para la edición del texto a partir de la editio princeps, vid. Lacarra (2016).

16 Lacarra $(2014 ; 2015)$, quien descubrió el incunable, ofrece una visión mucho más completa de todos los datos previos conocidos antes del hallazgo del ejemplar, así como de la investigación llevada a cabo para reconstruir el camino que pudo haber recorrido desde su salida de la imprenta hasta las manos de su actual propietario, el Earl of Crawford (ISTC is00453300; GW 12880). 
en la corte, había desaparecido prácticamente a favor de una literatura asentada en la ortodoxia religiosa pero abierta en cierto modo al Humanismo. Las colecciones de cuentos medievales habían quedado relegadas al ámbito de los exempla y a la predicación. No obstante, es necesario tener en cuenta que, por ejemplo, la versión oriental del Sendebar ha llegado hasta nosotros conservada en una copia de esta centuria, indicador de que, al menos entre los sectores cultos, la obra continuaba leyéndose (Gómez Redondo, 2006: 105).

La Historia de los siete sabios de Roma pudo haber sido percibida por los lectores españoles de finales del siglo XV como una obra muy cercana al debate dialogado narrativo, pero el carácter folclórico y hagiográfico y los temas compartidos de muchos cuentos insertos con otras narraciones conocidas desde el periodo medieval favoreció que los lectores la percibieran como un elemento más de la atmósfera cultural de la que ellos formaban parte. Gómez Redondo (2006: 104-125) considera que la obra resultante de la traducción tendría cierta deriva hacia la ficción sentimental por acoger en su estructura el modelo de la disputa que se apoya en la defensa o vituperación de la mujer, línea que entronca con la misoginia, y que para este autor también se acercaría a la literatura de corte sentimental a través de algunos relatos. El motivo sentimental se haría más evidente en la ampliación del relato final, cuyo germen se encuentra en el cantar de gesta francés Amis et Amiles, donde el protagonista actúa como mediador de amores con su mejor amigo. En última instancia, supondría para este autor un nuevo proceso de narratividad más acorde con las novellae italianas debido a que "fuera del texto se halla un público que sabe valorar el incremento de intrigas, de personajes secundarios, de relaciones enunciativas y, sobre todo, de situaciones humorísticas" (Gómez Redondo, 2006a:126).

Para Patricia Cañizares (2011: 126); en cambio, la nueva traducción se vincularía con la pedagogía moral y se adecuaría a un nuevo tipo de público y nuevas formas de recepción, así como un deseo por parte de los nuevos lectores que surgían de disfrutar en lengua vernácula de obras de este tipo más allá de los predicadores.

Independientemente de todo lo anterior, se percibe una cierta evolución en la configuración de las historias insertas de la traducción que dan lugar a un resultado final que respondería al modelo oriental de literatura didáctica, donde el didactismo habría pasado a un segundo plano con predominio de la finalidad lúdica y de entretenimiento (De la Torre Rodríguez, 1992: 70-71). Es decir, podemos hablar de la difuminación de los orígenes orientales tal y como se presentaban en los primeros momentos de andadura de la colección. 
Un estudio un poco más detallado del texto traducido nos permite ver que se conservan los principales cambios operados, tanto en el relato-marco como en las narraciones insertas, en el paso de la colección a Occidente. La narración central en sus principales rasgos se mantiene, continúa el intercambio dialéctico entre madrastra y consejeros y el silencio del príncipe, pero modifica aspectos relativos a la localización de la historia y al papel desempeñado por muchos personajes. La acción se traslada a Roma, cabeza del Imperio Romano de Occidente, referente cultural importante en Europa y ciudad de prestigio también durante la Edad Media, aunque en otras versiones podemos encontrar como ambientaciones preferidas Constantinopla o la isla de Sicilia, lugares igualmente reconocibles para un lector medieval occidental. El traslado de la acción a la antigua capital del Imperio está estrechamente relacionado con los nombres de los protagonistas, el monarca se llamará Ponciano y su hijo Diocleciano, ambos con claras reminiscencias romanas.

Con respecto a los personajes y a sus acciones dentro del relato, el monarca pasa de la poligamia a la monogamia y de tener noventa esposas a enviudar para casarse de nuevo, aspecto mucho más acorde con la mentalidad religiosa cristiana de Occidente. Sin embargo, el hecho destacable del relato se opera en el sabio encargado de la educación del infante. Sendebar o Çendubete, quien daba nombre al ciclo oriental, desaparece para dar paso a siete sabios individualizados con nombres ${ }^{17}$ que identifican el nuevo ciclo. Estos sabios, a su vez, asumirán el puesto de narradores de las historias que en el Sendebar lo habían ocupado los consejeros del rey.

Las narraciones insertas también dan cuenta de la adaptación de la colección a la mentalidad de su nuevo territorio de recepción. Su número se ha reducido considerablemente, pues los sabios ya no narrarán dos historias, se centrarán en exclusiva en la narración de tono misógino para conseguir el descrédito de la madrastra, y el infante cerrará el conjunto de relatos insertos con una única historia. Además, solo se conservan cuatro narraciones coincidentes con el Sendebar oriental, canis, aper, avis y senescalcus. ${ }^{18}$ Las narraciones restantes habrían circulado previamente por la Europa del siglo XII como parte de la oralidad y más acorde a la mentalidad cultural e ideológica

17 La Historia de los siete sabios de Roma da como nombres de los sabios Pantilla, Léntulo, Cratón, Malquidra, Josepho, Cleofás y Joaquín.

18 El resto de relatos que se añaden son arbor, puteus, gaza, sapientes, tentamina, Virgilius, medicus, amatores, inclusa, vidua y vaticinium + amici. La denominación latina proviene de la crítica decimonónica. 
del momento. Gracias a la flexibilidad de la estructura narrativa de la novelamarco, que puede actuar como contenedor y receptáculo de historias, estas se habrían introducido sin alterar el sentido de la narración principal adquiriendo un nuevo significado a su servicio. El relato Virgilius constituye el modelo más representativo de este proceso.

\section{La occidentalización de los Siete sabios de Roma: el ejemplo de Virgilius}

Virgilius, como una más de las narraciones insertas en el marco narrativo, se erige uno de los ejemplos más representativos del proceso de occidentalización que sufrió los Siete sabios en la configuración de la rama europea de la colección, proceso que se vio sustentado, como ya se ha comprobado, por la libertad de este género. Presente en prácticamente todas las familias de la rama occidental de transmisión, muchos de los aspectos que contiene habrían circulado por Europa entorno al siglo XII cuando la colección comienza su andadura por el continente, hecho que apunta a su presencia ya en el arquetipo original.

La figura de Virgilio, protagonista del relato, representa ese vínculo del ciclo occidental con el imaginario europeo medieval. Su imagen resulta de un contexto en el que la materia clásica y, sobre todo, la materia troyana comienzan a ser fuente de traducciones y reelaboraciones por parte de las clases doctas, que acercarán las obras clásicas a una mentalidad puramente feudal, tanto en el tratamiento de temas y motivos, como en la presentación del ambiente en el que se mueven los personajes (Comparetti, 1872: 6-8). La predilección por el ciclo troyano dará lugar a que su autor más representativo cobre relevancia sobre sus homólogos latinos en los ambientes cultos y eclesiásticos, ${ }^{19}$ y sufra en los primeros años de la Edad Media un proceso de ficcionalización que lo introducirá en una sociedad típicamente feudal, el Dolophatos de Juan de Alta Silva o la Divina Comedia son ejemplos representativos. Durante su transformación literaria, Virgilio adquirirá un estatus de sabio y se introducirá en una esfera de intelectuales reales o fruto del imaginario, muchos de ellos proceden-

19 Benoît de Sainte-More ejemplifica muy bien ese proceso de feudalización de obras épicas latinas en su Roman d'Éneas, inspirado directamente en la Eneida y de la que pretende ser una adaptación, pero en la que se introducen algunos temas pertenecientes al ideario contemporáneo al autor, como la importancia que se le conceden a las historias amorosas de Eneas con Dido y Lavinia o ciudades y personajes adaptados a los usos y costumbres del mundo feudal. Vid. Comparetti, 1872: 9. 
tes de la Antigüedad, a los que se les dotará de propiedades y poderes mágicos, alcanzando incluso la consideración de $\operatorname{magos}^{20}$ (Lee, 2013: 148).

Los antecedentes de esta literaturización se remontan a la época clásica, tanto en el ámbito cristiano como en la literatura pagana, momento en el que ciertos tintes proféticos, las proliferación de pseudobiografías y su propia producción literaria - tanto en la Eneida como en las Geórgicas se encuentran elementos que podríamos considerar como mágicos o maravillosos-, contribuyeron a desembocar en la faceta de mago ya en la Edad Media. Su posterior introducción en biografías y vitae con un alto contenido ficcional terminarán por redondear su faceta de hacedor. ${ }^{21}$ En un estadio más avanzado, estas habilidades mágicas, en un principio asociadas con propiedades benéficas fruto del saber y la naturaleza, acabarán por tornase en degradaciones posteriores en las propias de un nigromante que ha aprendido esas artes pactando con demonios (Graf, 1923: 562).

La irrupción del folclore en la cultura alta en el siglo XII dio lugar a que lo «popular»o «maravilloso» se introdujese incluso en las esferas escolásticas (Lee, 2013: 149). Virgilio y las leyendas virgilianas aparecerán en obras cultas en latín y vinculadas con el área de Nápoles, donde se creía que estaba su sepulcro y donde el poeta habría pasado algunas épocas de su vida (Comparetti, 1872: 21). Los extranjeros que visitaron la ciudad recogieron esas historias y las llevaron a sus países de origen, trasladando esta vertiente del poeta a la literatura escrita, donde las leyendas virgilianas comenzarán a ramificarse. Así, Conrado de Querfurt, obispo de Hidesheim y canciller del emperador Enrique IV, habla de un paladio que impedía que la ciudad fuese destruida, de una habitación que preservaba la carne de la podredumbre o de la estatua de un arquero que protegía Nápoles de las erupciones del Vesubio. Gervasio de Tilbury en sus Otia Imperalia (1212) coincide en muchas de las leyendas con el anterior, y menciona una cabeza con dos rostros que marcaban los destinos de

20 En el caso de Virgilio, habría una relación con la etimología del término poeta, proveniente del griego poiètēs 'hacedor' y cuyo equivalente en latín, vates, aunaría las facetas de vidente y poeta, y con una errónea interpretación de los manuscritos medievales que aludirían a sus padres como Magus y Magia. Vid. Ziolkowski, 2015: 66.

21 Para Comparetti existiría una distinción clara entre el Virgilio escolástico presente, por ejemplo, en el Dolophatos o en la obra dantesca, y el Virgilio mago fruto del ideario popular. Lee (2013: 147) y Ziolkowski (2015: 63) no consideran esta distinción como operativa, entienden que ambas facetas se interrelacionan íntimamente. Para este último, la faceta mágica de Virgilio es en parte deudora de los conocedores de su poesía más que de una creencia de origen popular, desde un primer momento hubo tendencia a potenciarlo por encima de otros autores y a considerarlo como depositario de todas las ramas del saber. Vid. Ziolkowski, 2015: 67. 
quien pasase por debajo (Comparetti, 1872: 21-28). John de Salisbury, el primero en recoger relatos virgilianos, alude en su Policratus (1159) a una mosca de bronce elaborada por el poeta que mantenía a las homólogas reales alejadas de la ciudad. El último de ellos, Alexander Neckam, da cuenta en su De naturis rerum (1180-1190) de narraciones que no se habían recogido previamente y que ya proporcionan datos sobre la expansión de la leyenda por Europa. Frente a los otros autores, nunca estuvo en Nápoles, lo que permite ver una nueva asociación de las leyendas virgilianas con la ciudad de Roma, aspecto en el que me centraré más adelante (Graf, 1923: 541-542). ${ }^{22}$

En estos autores, en última instancia, se percibe el entusiasmo de muchos viajeros que se sintieron fascinados al verse inmersos en leyendas propias de la mitología grecorromana y encontrarse ante la presencia de talismanes de indudable origen oriental. Nápoles y la isla de Sicilia constituyeron enclaves importantes en las rutas mediterráneas procedentes de Oriente durante los siglos IX y x, y uno de los caminos más frecuentados por los judíos radanitas en sus viajes comerciales hacia el sur de Francia (Lee, 2013: 154). La fama de Virgilio habría suscitado tanto interés que enseguida se convirtió en imán de muchas leyendas orientales, incluida la habilidad de hacedor de talismanes o apotropeia ${ }^{23}$ una serie de objetos capaces de influir en el mundo natural, humano o no humano, con la función de proteger o repeler organismos vivos, y para cuya elaboración se requería la presencia de una figura conocida que le

22 Son muchas las posturas surgidas en torno a los posibles orígenes de los mirabilia virgilianos. Para Comparetti (1872), las leyendas indiscutiblemente habrían tenido su origen, gestación y difusión en la ciudad de Nápoles fruto del cariño del pueblo hacia el poeta, opinión sustentada también por la ideología nacionalista del Risorgimento. Vietor (1877) considera, por su parte, que las leyendas no deben asociarse en exclusiva con la ciudad italiana, habrían surgido fundadas en el concepto que tenían los literatos de Virgilio y de sus saberes sobrenaturales. Graf (1923), a su vez, aúna ambas posturas, no descarta el origen literario de las leyendas pero considera que la relación entre los literario y lo popular habría sido cíclica y de ella habría surgido esa asociación entre Virgilio, las leyendas y Nápoles. No hay que ignorar que en las leyendas virgilianas encontramos muchos motivos folclóricos presentes en otras culturas y paralelismos con obras similares atribuidas a otras figuras como Apolonio de Tiana, Aristóteles o Hipócrates. Spargo (1934) defiende que las leyendas no habrían podido surgir sin la condición de hombre sabio de la que gozaba en la tradición medieval culta y alude a la presencia de los orígenes maravillosos en las leyendas virgilianas. En última instancia, teoriza sobre la posibilidad de que muchos de los extranjeros que recogieron las leyendas las hubiesen creado, al no documentarse en las gentes de Nápoles pero sí en sus obras.

23 Ejemplos de apotropeia en ámbito bizantino los encontramos en las estatuas creadas por Apolonio de Tiana para impedir la entrada de serpientes o en la creación una estatua atribuida a Teodoro de Samos en el siglo iv para proteger de las erupciones del Etna. Incluso se documentan en París, ya en la Europa occidental, y en tiempos de Gregorio de Tours (siglo vi) para alejar una plaga de moscas. Vid. Baader y Weinryb, 2016: 2-3; Comparetti, 1872: 31-32; Krappe, 1932: 273. 
atribuyese su condición mágica, «a certain known maker, without whose authorship the object would be thought of merely as a work of art» (Baader y Wineyb, 2016: 5-6). Los mirabilia virgilianos se habrían forjado a partir de objetos u obras de arte preexistentes en la ciudad de Nápoles, y la llegada de leyendas a través de la ruta mediterránea bizantina y el reconocimiento del que gozaba el poeta en la ciudad italiana pudieron dar lugar a la asociación entre leyenda y monumento. Tras la desaparición de este último, surgiría la leyenda y su posterior difusión por Europa incorporando fabulaciones y cambios.

Encontramos las leyendas virgilianas ya completamente asentadas y difundidas por Europa en la segunda mitad del siglo XIII. Las colecciones de exempla en latín sirvieron de vía de difusión, gracias sobre todo a la influencia del Speculum historiale de Vincent de Beauvais, que recogió muchos mirabilia virgilianos y sirvió de base a los compiladores de exemplarios. El Virgilio mago aparecerá como protagonista de exempla en colecciones como la Scala Coeli de Juan Gobi o los Gesta Romanorum, donde la importancia no radicará tanto en su individualización como Virgilio mago sino en la moralización conjunta de la historia (Berlioz, 1985: 100-101). Junto con la predicación, la literatura que empezaba a surgir en las diferentes lenguas vernáculas europeas hará un hueco a la figura medieval de Virgilio, y este aparecerá en una docena de obras entre poemas, crónicas y relatos como la Image du Monde de Metz (mediados del siglo XIII), el Cléomadès (finales del siglo XIII), el Renard de Contrefait (comienzos del siglo XIV) o el Fleur des histories (mediados del siglo XIV). En este tipo de relatos, Virgilio se entremezclará también con la figura del amante burlado por las tretas femeninas ${ }^{24}$ dentro de la línea misógina que se desarrolló en la Edad Media. Ya más avanzado el Medievo, surgirán una serie de biografías ficcionales del poeta que se centrarán especialmente en sus leyendas y mirabilia, tales como el Myreur des Histors de Jean d'Outremeuse (mediados del siglo XIV) o el anónimo Faictz merveilleux de Virgile, una obra que nació en el siglo XIV destinada directamente para su difusión impresa y que conoció traducciones en inglés, francés y flamenco (Loicq-Berger, 2011: sp).

24 El relato más conocido es «Virgilio en la cesta», según el cual, al no haber aceptado el poeta casarse con una amante, esta lo dejó suspendido en una cesta cuando pretendía subir a su torre para su escarnio ante todos los habitantes de Roma, lo que suscitará diversos modos de venganza por parte del mantuano. La historia gozó de tanta popularidad que muchos monumentos de la ciudad fueron conocidos por las gentes como «torre de Virgilio» hasta ya entrado el siglo xv. Vid. Enciclopedia Virgiliana, 19841991: 553; Spargo, 1934: 281-285. Podemos encontrar ejemplos de este relato en la literatura española en el Libro de Buen Amor y en el Corbacho, en el primero de los casos para prevenir contra el pecado de la lujuria y, en el segundo, con intenciones claramente misóginas. 
Como testimonio en lengua vulgar, los Siete sabios de Roma es considerado como uno de los más importantes para la difusión de la leyenda virgiliana por varias razones. La primera de ellas, íntimamente relacionada con lo prolífico de esta familia del ciclo occidental de la obra, atañe a las numerosas traducciones a diversas lenguas vernáculas europeas en las que vamos a encontrar la obra a partir del siglo $\mathrm{xv}$, de la que es ejemplo la zaragozana Historia de los siete sabios de Roma. La otra razón se vincula con aspectos más puramente literarios pues, pese a los varios contextos en los que fue leída la obra (predicativos, lectura espiritual...) se va a mantener el carácter ficcional de la novela-marco, donde Virgilius va a ser una ficción más al servicio de la narratividad de la obra.

En líneas generales, el hilo argumental de la narración es el que sigue: en tiempos de César Octaviano vive Virgilio, quien es conocido por sus artes para construir artificios, entre ellos unas fuentes para el baño de los pobres y una estatua con un enigmático mensaje que, tras ser destruida por la avaricia de un clérigo, provoca la desaparición de las primeras. La codicia del emperador es tal que, ante las amenazas de rebelión de las otras provincias, Virgilio construye en una torre una estatua por cada provincia enemiga del Imperio, de tal manera que hagan sonar una campanita y alerten a los ciudadanos cada vez que se vaya a producir un ataque. Los reyes enemigos planean cómo destruirla para conquistar la ciudad, y para ello envían a tres caballeros que fingen encontrar cubas llenas de oro a través del sueño. El emperador, aunque en un primer momento es reticente a cavar bajo la torre de las estatuas ante la creencia de que allí se encuentra una de las cubas, acaba cediendo por su codicia. Los caballeros, con el beneplácito de este, terminan por derribar la torre, Roma es saqueada y el emperador es rociado con oro hirviendo a modo de castigo.

En el relato confluyen reminiscencias de varias leyendas y mirabilia virgilianos que se agrupan entorno a dos motivos centrales: Hic percute! y Salvatio Romae. A pesar de la aparente superposición de ambos en el relato, -los Siete sabios es el único testimonio que los menciona de manera conjunta,$-{ }^{25}$ la narración se centra casi en exclusiva en la Salvatio, aunque ambos motivos transcurren en la capital del Imperio Romano de Occidente. Una vez que las leyendas virgilianas adquirieron desarrollo y difusión fuera de las fronteras

25 Aunque ambas leyendas no habían aparecido unidas, sí debieron estar presentes conjuntamente en páginas de compilaciones medievales más tempranas y en los repertorios de oralidad de los narradores de historias ambulantes que conducían a los peregrinos franceses y normandos por las ruinas de Roma. Vid. Krappe, 1932: 272. 
italianas, se produjo un desplazamiento de las hazañas de Virgilio a Roma, pero manteniendo los motivos folclóricos asociados con la protección de la ciudad que presentaban en Nápoles (Lee, 2013: 147). Roma, como centro de la Cristiandad y núcleo de la Antigüedad Clásica, ejerció una fuerte atracción sobre las leyendas virgilianas que terminarán vinculándose con esta urbe, como resultado de la unión de la trascendencia del núcleo urbano y de la fama del poeta en la mentalidad medieval (Comparetti, 1872: 64-66). Para ello, fue fundamental el papel que desempeñaron los Mirabilia Urbis Romae, tratados de viaje confeccionados a modo de guía turística para la peregrinación que incluían leyendas asociadas con Roma ya desde principios de la Edad Media, y que pretendían dar cuenta del origen o del uso especial de algunos de sus monumentos. Como consecuencia, la ciudad se convirtió en foco de atracción de peregrinos en cuya mente se combinó la devoción por la Roma cristiana y la admiración por la Antigua Roma (Graf, 1923: 49). El traslado de las leyendas virgilianas a Roma y a los Mirabilia tuvo que haberse producido necesariamente a partir del siglo XII, siglo en el que todavía aparecen vinculados con Nápoles, y una vez que la leyenda se hubo difundido por la capital italiana.

Hic percute! en la Historia de los siete sabios de Roma aglutina aspectos de tres leyendas virgilianas diferentes: la imagen del fuego eterno, los baños medicinales y la estatua protectora, que unifica los dos anteriores. Testimonios de un fuego que nunca se apagaba se localizan ya en los Mirabilia, donde se menciona la existencia en Roma de un candelabro de autoría anónima cuya llama era imperecedera. Habrá que esperar a la Image du monde, el Cléomadès o los Siete sabios para ver a Virgilio como artífice. La estatua protectora habría supuesto el germen de la leyenda, cuyos antecedentes más directos se encuentran en el arquero que protegía Nápoles de las erupciones del Vesubio según los testimonios de Querfurt. Esta estatua se trasladará a Roma y pasará a ser la protectora de los múltiples tesoros amasados bajo el imperio de Augusto con un enigmático mensaje, Hic percute!, que da nombre al motivo, y posteriormente pasará a ser obra de Virgilio y a encargarse de la protección del fuego eterno. Con respecto a la destrucción de la estatua a manos de un clérigo avaro, la variante de esta familia de transmisión se mantiene cercana a las versiones más antiguas (Graf, 1923: 129). Posteriormente, el relato, al igual que sucedió con muchas historias virgilianas, se verá atraído hacia personajes con nombres propios. ${ }^{26}$ La inclusión de las fuentes como otra de las creaciones

26 Un ejemplo de ello es Gerberto, el futuro papa Silvestre II, quien fue dentro de la mentalidad popular medieval una figura a menudo vinculada con la magia. Entre las muchas leyendas que se le asocian se 
virgilianas protegidas por la estatua resulta anómala, pero sin duda sus antecedentes se encuentran en los baños de Pozzuoli, situados a las afueras de Nápoles y de gran popularidad en el Medievo por sus propiedades medicinales, y atribuidos como tantas leyendas a la mano del poeta, quien los habría creado para solaz de aquellos pobres que no se podían costear los servicios médicos (Spargo, 1934: 17).

Si se puede hablar de un motivo que alcanzó gran popularidad en el Medievo, ese fue la Salvatio Romae o Salvatio Civium. Parte de su éxito es, sin duda, deudor de la labor de Neckam, el primero en incorporar a Virgilio como artífice más allá de Nápoles, el responsable en parte de su difusión en Europa y cuya versión ha sido transmitida, en mayor o menor medida, en testimonios posteriores (Spargo, 1934: 117). Según el autor, Virgilio elaboró en Roma un palacete dotado de una estatua con una campanita por cada reino subyugado por el Imperio, de tal manera que, ante la rebelión de uno de ellos, la correspondiente estatua hacía sonar la campanita para alertar a la población y la estatua central, formada por un hombre a caballo, apuntaba con su lanza en la dirección de esa provincia.

Las primeras versiones se documentan en los Mirabilia Urbis Romae con autoría anónima, pero podemos hablar de madurez en la leyenda en estas guías, tal y como la transmite Neckam, en el siglo XII, de donde probablemente la tomase el autor. No obstante, los orígenes del motivo de la Salvatio existían ya en el siglo VIII, como resultado de la confluencia de una serie de hechos muy diversos que tienen como punto central la potencia de la ciudad y la superioridad del Imperio Romano en la visión de los pueblos enemigos de Roma. Lo anterior, unido al gusto por lo sobrenatural que se genera en la Edad Media, derivaría en este tipo de explicaciones sobre su supremacía. A la versión definitiva y a su introducción en los Mirabilia contribuyeron los múltiples peregrinos que visitaron la ciudad, a los que se les narraban las historias de monumentos como el Panteón que a menudo contenían estatuas mágicas (Poucet, 2013: sp). El Capitolio, centro de la vida política y administrativa de Roma, fue el sitio preferido para ubicar la Salvatio en un primer momento, trasladándose después a otros edificios emblemáticos de la $\operatorname{ciudad}^{27}$ (Graf, 1923: 158-159).

encuentra la de la estatua que custodia el tesoro y el fuego que nunca se apaga, una de las variantes de la historia asociada con Virgilio, Vid. Comparetti, 1872: 78-80.

27 Escritores romanos como Plinio o Suetonio dan cuenta de la existencia del Porticus ad nationes, una puerta mandada construir por Augusto donde colocó una estatua por cada una de las naciones existentes. Vid. Poucet, 2013: sp. 
Para Graf (1923: 157), el germen de la leyenda sería indudablemente occidental, como todas las contenidas en los Mirabilia, y se habría gestado por completo en la ciudad de Roma. Su justificación radicaría en la existencia de relojes y estatuas móviles que adornarían los edificios de la ciudad y en la costumbre romana de consagrar lugares con estatuas para contener a los enemigos bárbaros del Imperio. Frente a la opinión del estudioso italiano, hay motivos para pensar en una posible fuente oriental del relato que se habría introducido en Occidente, y cuyo origen sería la existencia en el mundo árabe y bizantino de construcciones y motivos que aseguraban la protección frente a los enemigos. ${ }^{28}$

Así, encontramos variantes del relato en las que las estatuas son sustituidas por un espejo situado en lo alto de una torre que permitía ver todo lo que sucedía en los territorios del Imperio, ejemplos de ello son algunas variantes del relato del ciclo de nuestra obra, y cuyos antecedentes se encuentran en el faro de Alejandría, donde se cuenta que Alejandro Magno situó un espejo con esa finalidad protectora (Krappe, 1932: 276). Del mismo modo, la destrucción de la Salvatio, de alusiones escasas en los Mirabilia o en la obra de Neckam, cuenta con antecedentes en la literatura árabe. Según la narración de un historiador árabe, el califa Al-Walid fue engañado por un bizantino que le hizo creer que bajo el faro de Alejandría existió un tesoro y lo convenció para derribarlo (Lacarra, 1999: 99). La versión que ha sido transmitida por la Historia de los siete sabios de Roma es heredera directa de Neckam y los Mirabilia, pero el desarrollo narrativo pudo provenir del cruce con alguna versión que contuviese el espejo, quizás perteneciente a la propia rama occidental del ciclo.

Los autómatas, presentes en ambos motivos del relato, son igualmente deudores de la herencia oriental. Definidos como «cualquier aparato que posea un mecanismo capaz de producir cierta movilidad por sí mismo, llamándose por ello semimovente (...), que imita o reproduce la figura y movimientos de un ser vivo, mayormente de la especie humana» (Duce, 2016: XXII), los autómatas han sido una constante en las letras universales y, como máquinas, se han desarrollado incluso en las sociedades más primitivas. Hefesto, Dédalo y Prometeo son los principales constructores de autómatas de la literatura occidental, lo que remite necesariamente a la cultura helena como la mayor propulsora de tratadística sobre la construcción de este tipo de figuras articuladas, y a su

28 Testimonios hablan, por ejemplo, de la existencia en Constantinopla de una estatua de Justiniano que prevenía de los ataques de los persas y de una estatua fenicia de Hércules en Cádiz que ahuyentaba a todos los que llegaban con malas intenciones. Vid. Krappe, 1932: 274-276. 
ficción literaria como pionera en Europa. La Escuela de Alejandría se convirtió en centro de pensadores y matemáticos griegos que dedicaron parte de su producción al desarrollo de autómatas, bien como figuras individualizadas, bien como parte de un conjunto mucho más complejo. Su irrupción en la literatura medieval occidental se debe a Herón de Alejandría, miembro de dicha escuela y heredero de las ideas aristotélicas y de los principios de Arquímedes, que dedicó su vida a la elaboración de tres tratados que podríamos denominar pseudo-científicos y mecánicos orientados a la construcción de autómatas. El llamado corpus herónico - conjunto de todas sus obras y preceptos mecánicos-, penetró ampliamente en Bizancio desde donde pasó al mundo árabe que, como gran admirador de la mecánica griega, añadirá sus propias innovaciones.

Los autómatas se introdujeron más tarde en el imaginario medieval en todos sus ámbitos, incluido el literario, donde formarán parte de lo maravilloso mecánico, término acunado por Cacho Blecua (1987-1988: 128) para aludir a cualquier tipo de artificio que, si bien alejado de lo natural, causa asombro o admiración y se debe en parte a la intervención humana. No sorprende, por tanto, encontrar en los Mirabilia fantasías de este tipo.

La mecánica, pese a no gozar durante la Edad Media cristiana del interés y desarrollo que alcanzó entre griegos y árabes, con el avance de los estudios universitarios pasará a integrarse en las artes liberales en los siglos XII y XIII (Duce, 2016: XXI) y se asociará con grandes intelectuales europeos y con figuras rodeadas de un halo mágico como Merlín o el propio Virgilio: «When distance in both time and space had cast a romantic haze over these mechanical toys of past ages they lost their cogs and pulleys and water tanks and become wondrous creations of that incomparable medieval Wizard of Oz, Virgil the necromancer» (Spargo, 1934: 135). Los autómatas pervivirán en la literatura española más allá de la Edad Media, y alcanzarán gran popularidad en el Renacimiento gracias a los libros de caballerías, ${ }^{29}$ donde se considerarán como un embellecimiento y un atractivo más de la obra literaria y suscitarán en personajes y lectores el miedo por lo irracional o lo incontrolable y, en última instancia, la admiración por lo extraordinario (Alvar, 2004: 51).

29 Durante el Renacimiento se revitalizan las obras de Herón y los tratadistas de la Escuela de Alejandría que se traducen e intentan llevarse a la práctica. Los jardines de los aristócratas se llenaron de figuras automatizadas construidas por mecánicos de prestigio, por lo que no debe sorprender que este tipo de construcciones se mantuviesen en un género de tanto auge en el xvi como los libros de caballerías. Sobre su presencia en estos libros, resultan imprescindibles los trabajos de María del Rosario Aguilar Perdomo (2006; 2008) y la reciente publicación de Jesús Duce (2016). 


\section{Conclusiones}

La anónima Historia de los siete sabios de Roma contó con un gran recorrido a sus espaldas que tuvo su máximo momento de esplendor durante el periodo medieval. Como obra literaria, fue fruto de numerosos ámbitos de recepción y usos, ya fuese espejo de príncipes y guía de conducta para los buenos soberanos en su vertiente oriental, ya fuese la lectura silenciosa de corte espiritual o el material auxiliar en la predicación para prevenir contra la maldad de las mujeres en algunas familias occidentales. Las traducciones castellanas que se realizaron en el siglo XV a partir de versiones de este último ciclo no son sino una muestra más de adaptación a nuevos géneros literarios para cubrir los horizontes de expectativas de los lectores, en su deriva más sentimental o como lectura en la línea de la pedagogía moral. En última instancia, la colección también conoció, gracias a la imprenta, una difusión mayor, donde volverá a ser objeto de transformaciones según los deseos de los impresores y las exigencias del mercado editorial.

El relato Virgilius, que en boca de la madrastra entroncaría con la línea temática del soberano rodeado de buenos consejeros y pretendería conseguir de nuevo la condena a muerte del infante, es uno de los ejemplos más representativos de occidentalización de toda la colección. Bajo la forma que presenta en los Siete sabios, Virgilius, que mantiene reminiscencias de origen oriental como los autómatas y los talismanes, aglutina un conjunto de aspectos temáticos e ideológicos que conocieron un gran auge en la Edad Media europea. En última instancia, la inserción de este tipo de relatos considerados como propiamente occidentales, y de los que Virgilius no es más que otro ejemplo, no es sino una garantía de la versatilidad que propone una obra estructurada en torno a un marco narrativo. El marco narrativo de los Siete sabios supo funcionar en su paso a Occidente como contenedor de los relatos más populares que circulaban en ese momento en la tradición oral de la Europa en la que empezaba a difundirse, lo que puede considerarse como una de las principales claves para su perdurabilidad durante tantos siglos.

\section{Referencias bibliográficas}

AGUILAR PERDOMO, M. R. (2010), «Algunos ingenios y artificios hidráulicos en la arquitectura maravillosa de los libros de caballerías españoles», en L. von der Walde Moheno, C. Company, A. González (eds.), Expresiones de la cultura y el 
pensamiento medievales, México, El Colegio de México; Universidad Nacional Autónoma de México; Universidad Autónoma Metropolitana, pp. 273-290.

ALVAR, C. (2004), «De autómatas y otras maravillas» en N. Salvador Miguel, S. López-Ríos, E. Borrego Gutiérrez (eds.), Fantasía y literatura en la Edad Media y los Siglos de Oro, Pamplona, Universidad de Navarra, pp. 29-54.

ALVAR, C. (2010), Traducciones y traductores: materiales para una historia de la traducción en Castilla durante la Edad Media, Alcalá de Henares, Centro de Estudios Cervantinos.

ARTOLA, G. (1978), «The Nature of the Book of Sindibad», en H. Niedzielski; H. R. Runte; W. L. Hendrickson (eds.), Studies on the Seven Sages of Roma and Other Essays in Medieval Literature. Dedicated to the Memory of Jean Misrahi, Honolulu-Hawaii, Educational Research Associates, pp. 7-31.

BAADER, H. y I. WEINRYB (2016), «Images at Work: On Efficacy and Historical Interpretation», Representations, 133, pp. 1-19.

BENFEY, T. (1966), Pantschatantra. Fünf Bücher indischer Fabeln, Märchen und Erzählungen. Aus dem Sanskrit übersetzt mit Einleitung und Anmerkungen versehen [1859], Hildesheim, Georg Olms Verlag, 2 vols.

BERLIOZ, J. (1985), «Virgile dans la littérature des exempla (xiIIe-Xve siècles)», en Lectures médiévales de Virgile: Actes du colloque organisé par l'École Française de Rome (Rome, 25-28 octobre 1982), Roma, École Française de Rome, pp. 65120 .

CAMPBELL, K. (1975), The seven sages of Rome: edited from the manuscripts, with introduction, notes and glossary, Ginebra, Slatkine Reprints.

CÁNDANO FIERRO, G. (1995), «La mujer como portadora de peligro: 'Esto dize el decreto'», Medievalia, 21, pp. 1-16.

CAÑIZARES FERRIZ, P. (1999a), «La nouella de Diego de Cañizares y su original latino (I)», Cuadernos de Filología Clásica. Estudios Latinos, 16, pp. 279-319.

CAÑIZARES FERRIZ, P. (1999b), «La nouella de Diego de Cañizares y su original latino (II)», Cuadernos de Filología Clásica. Estudios Latinos, 17, pp. 143-175.

CANIIZARES FERRIZ, P. (2011), Traducción y reescritura. Las versiones latinas del ciclo Siete sabios de Roma y sus traducciones castellanas, Valencia, Institució Alfons el Magnànim; Diputación de Valencia.

COMPARETTI, D. (1872), Virgilio nel Medio Evo, Livorno, Coi tipi di Francesco Vigo, II.

DUCE, J. (2016), Antología de autómatas en los libros de caballerías, Alcalá de Henares, Universidad de Alcalá Servicio de Publicaciones; Instituto Universitario de Investigación Miguel de Cervantes.

Enciclopedia Virgiliana (1984-1991), Roma, Istituto della Enciclopedia Italiana.

EPSTEIN, M. (1958), «Mishlè Sendebar: New Light on the Transmission of Folklore from East to West», Proceedings of the American Academy for Jewish Research, 27, pp. 1-17. 
EPSTEIN, M. (1959), «The Manuscripts, Printed Edition and Translations of Mishlè Sendebar», Bulletin of the New York Public Library, 63, pp. 68-87.

EPSTEIN, M. (1967), Tales of Sendebar. An Edition and Translation of the Hebrew Version of the Seven Sages Based on Unpublished Manuscripts, Philadelphia, Jewish Publication Society of America.

GÓMEZ REDONDO, F. (2006), «La disolución de la cuentística oriental en el siglo XV», en M. J. Lacarra, J. Paredes (eds.), El cuento oriental en Occidente, Granada; Comares, Fundación Euroárabe de Altos Estudios, pp. 95-127.

GONZÁLEZ PALENCIA, A. (1946), Versiones castellanas del Sendebar, MadridGranada, Centro Superior de Investigaciones Científicas.

GRAF, A. (1923), Roma Nella Memoria E Nelle Immaginazioni Del Medio Evo. Torino, Casa Editrice Giovanni Chiantore.

HARO CORTÉS, M. (2015), «De Balneator del Sendebar a Senescalcus de los Siete sabios: del "exemplo" al relato de ficción», Revista de Poética Medieval, 29, pp. 145-175.

JAUNZEMS, J. (1978), «Structure and Meaning in the Seven Sages of Rome», en H. Niedrickson, H. R Runte, W. L. Hendrickson (eds.), Studies on the Seven Sages of Rome and Other Essays in Medieval Literature, Hawaii, Educational Research Associates Honolulu, pp. 43-62.

KRAPPE, A.H. (1932), «Studies on the Seven sages of Rome», Archivium Romanicum, XVI, 2, pp. 271-282.

LACARRA, M. J. (1979), Cuentística medieval en España: los orígenes, Zaragoza, Departamento de literatura española; Universidad de Zaragoza.

LACARRA, M. J. (1986), «Algunos datos para la historia de la misoginia en la Edad Media» en Studia in honorem prof. M. de Riquer, Barcelona, Quaderns Crema, pp. 339-361.

LACARRA, M. J. (ed) (1989), Sendebar, Madrid, Cátedra.

LACARRA, M. J. (1999), Cuento y novela corta en España I. Edad Media, Barcelona, Crítica.

LACARRA, M. J. (2014), «Las reescrituras de los cuentos medievales en la imprenta», en C. Esteve (ed.), El texto infinito. Tradición y reescritura en la Edad Media y el Renacimiento, Salamanca, Seminario de Estudios Medievales y Renacentistas [Actas 8], pp. 113-149.

LACARRA, M. J. (2015), «La hystoria de los siete sabios de Roma [Zaragoza: Juan Hurus, ca. 1488-1491]: un incunable desconocido», en Actas XV Congreso Internacional de la Asociación Hispánica de Literatura Medieval. Centro Internacional de Investigación de la Lengua Española (Cilengua. San Millán de la Cogolla, 8-14 septiembre de 2013, pp. 755-771.

LACARRA, M. J. (2016), Cuentos medievales (de Oriente a Occidente). Calila e Dimna, Sendebar. Libro de los engaños de las mujeres, Siete sabios de Roma, Madrid, Biblioteca Castro; Fundación José Antonio de Castro. 
LACARRA, M.J. y J.M CACHO BLECUA (1977), «El marco narrativo del Sendebar», en Homenaje a Don José María Lacarra de Miguel en su jubilación del profesorado: Estudios Medievales, Zaragoza, Anubar, II, pp. 223-243.

LEE, C. (2013), «Percorsi Mediterranei Del Libro Di Sindbad» en R. Morosini, C. Lee (eds.). Sindbad Mediterraneo. Per Una Topografia Della Memoria Da Oriente a Occidente, Lecce, Prensa multimedia, pp. 139-155.

LOICQ-BERGER, M.P. (2011), «Un autre Virgile. Le regard médiéval (2)», Folia Electronica Classica, 21. En línea: <http://bcs.fltr.ucl.ac.be/FE/21/VirMed/Vir2. htm> [Fecha de consulta: junio de 2016]

LOISELEUR-DESLONGCHAMPS, A. (1838), Essai sur les fables indiennes et sur leur introduction en Europe, Paris, Techener Librairie.

PALLARÉS JIMÉNEZ, M.A. (2003), La imprenta de los incunables en Zaragoza y el comercio internacional del libro a finales del siglo $\mathrm{x}$, Zaragoza, Institución «Fernando el Católico».

PERRY, B. E. (1959-1960), «The Origin of the Book of Sindibad», Fabula, 3, pp. 1-94. POUCET, J. (2013), «Des statutes aux clochettes et un miroir : deux intruments magiques pour protéger Rome», Folia Electronica Classica, 26. En línea: <http://bcs. fltr.ucl.ac.be/FE/26/STAT/Gen/Art_Intr.htm> [Consulta: junio de 2016].

RANK, O. (1991), El mito del nacimiento del héroe, Barcelona, Paidós.

RODRÍGUEZ DE MONTALVO, G. (1988-1991), Amadís de Gaula, J. M. Cacho Blecua (ed.), Madrid, Cátedra.

ROTH, D. (2000), «A Consideration of the Original Structure and the Transformation of the Historia septem sapientum troughout its Manuscript Tradition», Medieval Sermon Studies, 44, pp. 87-107.

RUNTE, H. R., KEITH WIKELEY Y J. FARRELL (1984), The Seven Sages of Rome and the book of Sindbad. An Analytical Bibliography, Nueva York; Londres, Garland (regularmente actualizada en la página web de la Seven Sages Society http:// myweb.dal.ca/hrunte/seven_sages.html)

SPARGO, J. W. (1934), Virgil the Necromancer. Studies in Virgilian Legends, Cambridge, Harvard University Press.

TARAVACCI, P. (2003), Sendebar. Il libro degli enganni delle donne, Roma, Carocci Editore.

TORRE RODRÍGUEZ, V. de la (1990), Variantes occidentales castellanas del Sendebar. Ciclo de los Siete sabios de Roma, tesis doctoral, Madrid, Universidad Complutense.

TORRE RODRÍGUEZ, V. de la (1992), «El relato intercalado en la Historia de los Siete Sabios de Roma», en M. Smerdou Altolaguirre, M. Bonsoms (eds.), El relato intercalado, Madrid, Sociedad Española de Literatura General y Comparada; Fundación Juan March, pp. 67-75.

TORRE RODRÍGUEZ, V. de la (1993), Los siete sabios de Roma, Madrid, Miraguano Ediciones. 
VIETOR, W. (1877), «Der Ursprung der Virgilsage», Zeitschrift fur romanische Philologie, I, pp. 165-178.

VILCHIS, J.C. (2004), «Mujeres “comunes” y “extraordinarias” en el Sendebar», Medievalia, 36, pp. 43-49.

ZIOLKOWSKI, J. (2015), «Virgil de Magician», en P. Boitani, E. de Rocco (coords.), Dall'Antico Al Moderno. Imagini Del Classico Nelle Letterature Europee, Roma, Fondazione Ettore Parattore; Edizioni di storia e letteratura, pp. 59-76. 